\title{
A new method to predict average flow velocity and conveyance capacity of meandering streams
}

Cristopher Alexander Gamboa-Monge ${ }^{1}$, Ana Maria Ferreira-da-Silva², Laura Segura-Serrano ${ }^{3}$, Isabel Guzmán-Arias ${ }^{4}$

Gamboa-Monge, C; Ferreira-da-Silva, A.M; Segura-Serrano, L; Guzmán-Arias, I. A new method to predict average flow velocity and conveyance capacity of meandering streams. Tecnología en Marcha. Edición especial. Movilidad Estudiantil 7, 2020. Pág 143-159.

doi) https://doi.org/10.18845/tm.v33i6.5286

1 Agricultural Engineering Student, School of Agricultural Engineering, Instituto Tecnológico de Costa Rica, Cartago, Costa Rica. Email: chrisgamong@gmail.com

2 Professor, Department of Civil Engineering, Queen's University, Kingston, Ontario, Canada. Email: anamaria.dasilva@queensu.ca

3 Ph.D. candidate, Department of Civil Engineering, Queen's University, Kingston, Ontario, Canada. Email: l.segura.serrano@queensu.ca

4 Professor, School of Agricultural Engineering, Instituto Tecnológico de Costa Rica, Cartago, Costa Rica. Email: iguzman@tec.ac.cr 


\title{
Keywords
}

Resistance to flow; divided resistance; resistance equation; resistance factor; cross-circulatory motion; stream curvature.

\begin{abstract}
This paper aims to be a contribution to the evaluation of the resistance factor of the alluvial meandering streams of natural origin. The well-known "divided resistance" approach, commonly adopted nowadays for straight streams with a bed covered by ripples and dunes is extended to include an additional term that considers the resistance due to the meandering of the stream. For the present analysis, 40 laboratory experiments and 285 field observations are evaluated, where it is found that the contribution of the meandering of the stream to its overall resistance may vary from negligible to very substantial, which depends on the stream geometric and flow conditions.

In addition, it is determined that the most influential components for the resistance factor in meandering conditions depend on the relation between channel-averaged flow depth $\left(h_{a v}\right)$ and the average grain size of the bed material $\left(D_{50}\right)$, the deflection angle of a meandering flow at the crossover $O_{i}\left(\theta_{0}\right)$, and also the relation between flow width $(B)$ and the channel-averaged flow depth $\left(h_{a v}\right)$; these relations are used to develop a mathematical expression capable to predict the resistance to flow due to the meandering of the stream. It is shown that the equation introduced in this paper leads to considerably improved predictions of average flow velocity and conveyance capacity of meandering streams, which is of significance for an improved management of inland waterways.
\end{abstract}

\section{Introduction}

River morphodynamics is the study of river bed and plan forms in response to erosion and sedimentation. In the context of river morphodynamics, it is essential to study energy losses in meandering streams, as they determine the resistance to flow of a stream exhibiting bends or curves [1].

Over time, several methods have been proposed to establish the additional resistance to flow due to the stream meandering. Such methods range from simple, empirically determined adjustments of friction factors to more complex, theoretically based formulations in terms of geometric and flow variables. According to James [2], the existing methods for predicting stage-discharge relationships for meandering channels give conflicting results and none have been reliably verified with independent data.

Some of the most prominent methods to quantify resistance to flow in meandering streams are: Soil Conservation Service (SCS) method [3], Linearized Soil Conservation Service (LSCS) method [3], and the method of Leopold et al. [4] subsequently modified by James and Wark [5]. These methods were developed under different conditions and some of them consider more variables than the others. Furthermore, it should be noted that most of the methods do not consider enough geometric variables and even the flow conditions are often neglected as parameters of the equations [6].

James [2], who tested some of the existing methods against different data, showed that ignoring bend losses gives unacceptably high errors in predicting discharge, with some methods giving worse results than others. This highlights the fact that it is necessary to analyze previous methods in order to verify what is the error level in the results, and seek a new method to solve this kind of problems, considering that they also have to be easy to apply routinely in practice [6]. 
The general objective of this work is to develop a new method to predict average flow velocity and stream conveyance capacity in meandering streams, fully considering the effect of bends on energy loss.

The specific objectives are as follows:

- To evaluate the existing methods for predicting average flow velocity and stream conveyance capacity;

- To develop a novel approach to quantify bend loss in meandering streams considering geometric and flow variables, and use it to implement a new method for predicting the average flow velocity and stream conveyance capacity;

- To assess the level of improvement in predictions by using the new method compared to previous methods.

\section{Present approach}

\section{Fundamentals}

In this paper, the resistance to flow will be expressed with the aid of Chézy resistance equation, namely:

$$
u_{a v}=c \sqrt{g S_{c} R_{h}},
$$

in which $c$ is the (dimensionless) Chézy flow resistance factor.

Following Langbein and Leopold [7], the centrelines of the streams will be idealized as sine-generated curves, given by $\theta=\theta_{0} \cos \left[2 \pi\left(I_{c} / L\right)\right]$, in which $\theta$ is deflection angle (see the schematic figure 1 ), $\theta_{0}$ is deflection angle of a meandering flow at the crossover $O_{i}$ (figure 1 ), $\mathrm{I}_{\mathrm{c}}$ is longitudinal coordinate along the centreline of a meandering flow $\left(I_{c}=0\right.$ at the crossover $\left.O_{j}\right)$, and $L$ is meander length measured along the channel centreline. As shown in da Silva and Yalin [6], the centreline curvature of sine-generated streams is given by

$B / R=\left[\theta_{0}\right.$ $\left.J_{0}\left(\theta_{0}\right)\right] \sin \left[2 \pi\left(I_{c} / L\right)\right]$, where $B$ is the flow width and $J_{0}\left(\theta_{0}\right)$ is the Bessel function of the first order and zero-th kind of $\theta_{0}$.

As follows from this expression, sine-generated curves exhibit a continuous variation of centreline curvature along the streamwise direction: $|B / R|$ is equal to zero at the crossover $O_{i}$ and reaches a maximum $B / R_{a}$ at the apex $a_{\mathrm{i}}$ :

$$
B / R_{a}=\theta_{0} J_{0}\left(\theta_{0}\right)
$$

The graph of $B / R_{a}$ is shown in figure 2. Observe how with the increment of $\theta_{0}$, the relative curvature $B / R_{a}$ first increases from zero onwards, reaching a maximum at $\theta_{0}=70^{\circ}$ and then decreasing as $\theta_{0}$ increases to $\approx 126^{\circ}$ (when the meander loops come into contact with each other, and the meandering pattern is destroyed). 


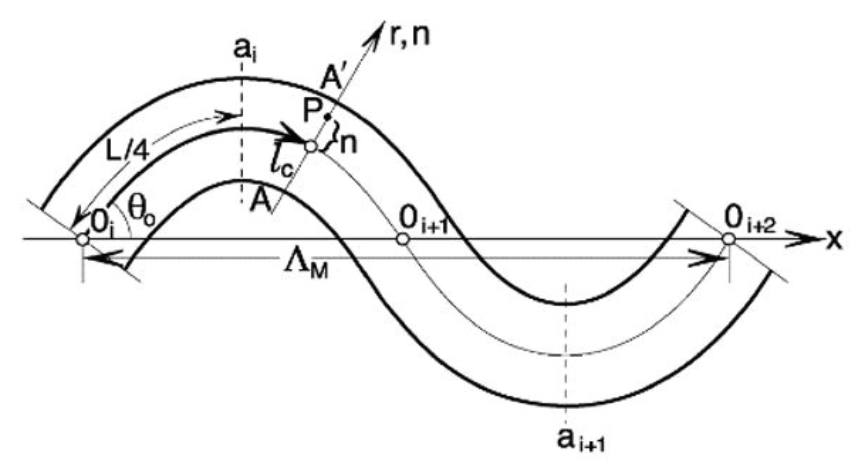

Figure 1. Definition sketch (after da Silva et al. 2008).

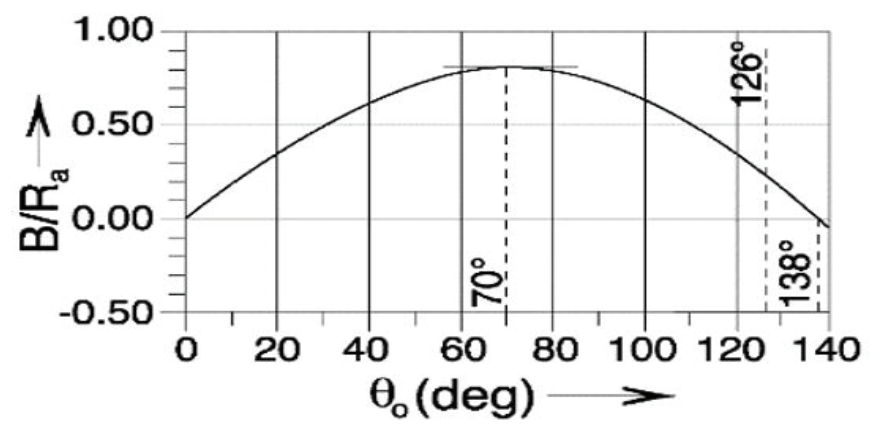

Figure 2. Plot of $B / R_{a}$ versus $\theta_{0}$ (after Yalin and da Silva 2001).

It can also be shown that the sinuosity $\sigma=L / \Lambda_{\mathrm{M}}$, where $\Lambda_{\mathrm{M}}$ is the meander wavelength, is uniquely related to $\theta_{0}$, as follows:

$$
\sigma=\frac{1}{J_{0}\left(\theta_{0}\right)}
$$

\section{Approach}

As is well-known, following Einstein and Barbarossa [8], Engelund [9], Yalin [10], etc., the prevailing approach to determine the flow resistance factor in a straight stream where the movable bed is covered by bed forms (dunes and/or ripples) is based on the division of total flow resistance into grain resistance and form resistance. This approach, commonly referred to as the "divided resistance" approach, considers the total bed shear stress as the sum of the bed shear stress due to the surface roughness $\left(\tau_{0}\right)_{f}$ and the bed shear stress due to the bed forms $\left(\tau_{0}\right)_{\Delta}$, i.e.

$$
\tau_{0}=\left(\tau_{0}\right)_{f}+\left(\tau_{0}\right)_{\Delta}
$$

It follows that the resistance factor $\mathrm{c}$ of flow can be expressed as 


$$
\frac{1}{c^{2}}=\frac{1}{c_{f}^{2}}+\frac{1}{c_{\Delta}^{2}}
$$

where $1 / c_{f}^{2}$ is the pure friction component of $1 / c^{2}$ and $1 / c_{\Delta}^{2}$ is the component of $1 / c^{2}$ due to bed forms.

Consider now a meandering stream. On the basis of the aforementioned, the increased resistance to flow can be treated as an increment of the bed shear stress $\tau_{0}$ due to the stream plan geometry, yielding

$$
\tau_{0}=\left(\tau_{0}\right)_{f}+\left(\tau_{0}\right)_{\Delta}+\left(\tau_{0}\right)_{M}
$$

where $\left(\tau_{0}\right)_{M}$ is the bed shear stress due to the meandering of the stream. Eq. (6) in turn implies

$$
\frac{1}{c^{2}}=\frac{1}{c_{f}^{2}}+\frac{1}{c_{\Delta}^{2}}+\frac{1}{c_{M}^{2}}
$$

where $1 / c_{M}^{2}$ is the component of $1 / c^{2}$ due to the meandering of the stream.

In the following, a suitable expression for $1 / c_{M}^{2}$ is developed on the basis of dimensional considerations and all the available laboratory and field data.

However, before proceeding further, the following should be noted.

1. The meandering of a stream induces the growth, in the vertical z-direction, of laterally adjacent deposition bars and pools (illustrated in figure 3). In the case of sine-generated streams, each bar+pool complex forms a large-scale erosion-deposition zone having the length $L / 2$. Elements of bed topography due to reasons other than the meandering of the stream, namely dunes and/ or ripples, can be superimposed on the large-scale bed deformation due to meandering. The term $1 / \mathrm{c}_{\Delta}^{2}$ in Eq. (7) is thus to be viewed as incorporating the effect of both dunes and ripples, as well as that of the meandering bed deformation. However, the bars and pools are, as a rule, rather flat at any stage of the meandering bed development. Their longitudinal and radial steepness can be expressed as

$\delta_{1} \approx \Delta /(L / 2)<2 h_{a v}$ $/ L$ and $\delta_{r}=\Delta /(B / 2)<2 h_{a v} / B$, respectively. Here $\Delta\left(=\Delta_{b}\right.$ or $\left.\Delta_{p}\right)$ implies the height of bars and the depth of pools, respectively. The contribution of the pools and bars to the overall resistance to flow is thus of secondary importance only. Considering this, in the following, this contribution will be disregarded - i.e. the only bed forms that will be considered are ripples and dunes.

2. As is well-known, the friction factor $c_{f}$ of a flow past a flat bed can be determined from the following expression (see e.g. [11], [6]):

$$
c_{f}=\frac{1}{\kappa} \ln \left(0.368 \frac{h_{a v}}{k_{s}}\right)+B_{s}
$$

when $\mathrm{K}$ is von Kármán constant $(\approx 0.4), k_{s}$ is granular roughness of the bed surface and $B_{s}$ is the roughness function. Following Kamphuis [12] and Yalin [13], in this work $k_{s}$ is identified with $2 D_{50}$ $\left(2 D_{50}=\right.$ average grain size of the bed material); and $B_{s}$ is determined from the following equation, due to da Silva and Bolisetti [14] (see also [6])

$$
B_{s}=\left(2.5 \ln \operatorname{Re}_{*}+5.5\right) e^{-0.0705\left(\ln \mathrm{Re}_{*}\right)^{2.55}}+8.5\left[1-e^{0.0594\left(\ln \mathrm{Re}_{*}\right)^{2.55}}\right]
$$

where $R e_{*}$ is the roughness Reynolds number $\left(=v * k_{s} / v\right.$, where $v_{*}=\left(g S_{c} h_{a v}\right)^{1 / 2}$ is shear velocity, and $v$ is fluid kinematic viscosity, in this work identified with $10^{-6} \mathrm{~m}^{2} / \mathrm{s}$ ). 
3. Following Yalin [10] and Engelund [9], the following expression is adopted for $1 / c_{\Delta}^{2}$ :

$$
\frac{1}{c_{\Delta}^{2}}=\frac{1}{2 h_{a v}}\left(\delta_{d}^{2} \Lambda_{d}+\delta_{r}^{2} \Lambda_{r}\right)
$$

where $\delta_{d}$ is dune steepness, $\Lambda_{d}$ is dune length, $\delta_{r}$ is ripple steepness and $\Lambda_{r}$ is ripple length.

In this work, the equations by da Silva and Yalin [6] for $\delta_{d}, \Lambda_{d}, \delta_{r}$ and $\Lambda_{r}$ were adopted (see [15]).

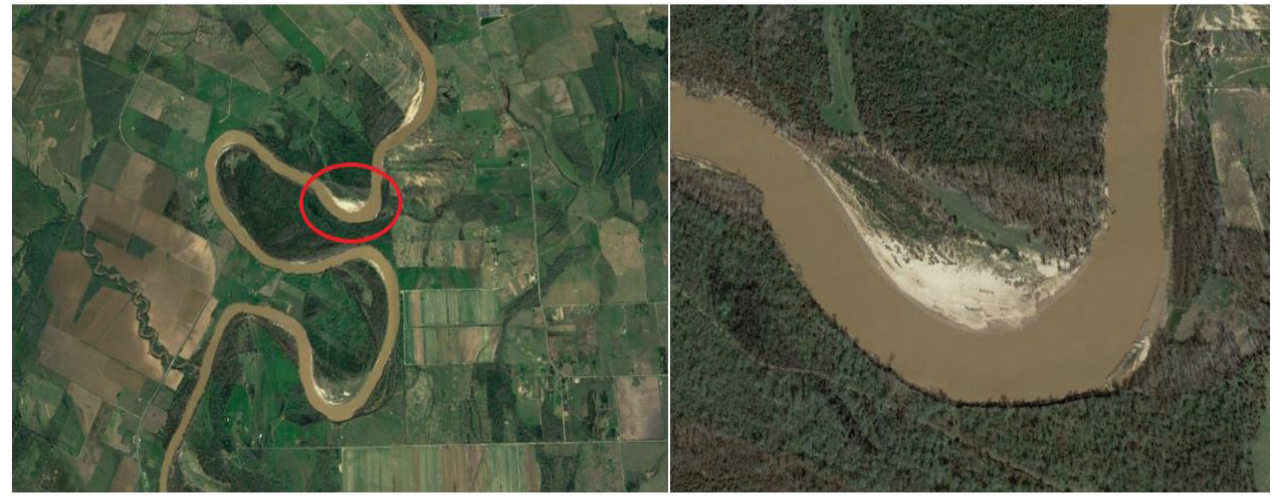

Figure 3. Example of typical features of a meandering river. Left: in the red circle its possible to see a point bar in the inner bank of the meander; right: zoom on the same point bar shown on the left picture. Brazos River, West of Monaville, Texas, United States of America. Image source: Google Earth, Landsat Copernicus, 2018.

\section{Variables determining $1 / \mathrm{c}_{\mathrm{M}}{ }^{2}$}

In this section, dimensional analysis is used to establish the variables upon which $1 / \mathrm{c}_{M}^{2}$ might depend.

The flow in a sine-generated channel having a naturally acquired deformed bed, centreline slope $S_{c}$ and the granular roughness $k_{s}$ is determined by the following $n=8$ characteristic parameters: $\rho, v$, $\theta_{0}, \Lambda_{M}, B, k_{s}, g S_{c}, h_{a v}$, where $\rho$ is fluid density, $v$ is fluid kinematic viscosity, $\theta_{0}$ is deflection angle at the crossover (at $I_{c}=0$ ), $\Lambda_{\mathrm{M}}$ is meander wavelength, $B$ is flow width, $g$ is acceleration due to gravity, $S_{c}$ is stream centreline slope and $h_{a v}$ is channel-averaged flow depth. Hence any characteristic $A$ of a sine-generated alluvial stream can be expressed as

$$
\mathrm{A}=f_{\mathrm{A}}\left(\rho, v, \theta_{0}, \Lambda_{M}, B, k_{s}, g S_{c}, h_{a v}\right)
$$

Using $\rho, v$, and $\mathrm{h}_{a v}$ as repeaters, and replacing $g \mathrm{~S}_{c}$ by ${ }^{\star} v$, we determine for the dimensionless counterpart $\Pi_{\mathrm{A}}$ of $\stackrel{a v}{A}$

$$
\Pi_{A}=\rho^{x} v^{y} h_{a v}^{z} A=\varphi_{A}\left(\theta_{0}, \Lambda_{M} / B, B / h_{a v}, h_{a v} / k_{s}, v_{*} k_{s} / v\right)
$$

Let us now identify $A$ in Eq. (11) with the channel-averaged flow velocity $u_{a v}$ and thus $\Pi_{A}$ in Eq. (12) with $h_{a v} u_{a v} / v$. Taking into account that $u_{a v}=c \cdot v_{*}$, and also that the characteristic wavelength $\Lambda_{M}$ of natural alluvial streams and the flow width $B$ are not independent, but rather related as $\Lambda_{M}=$ const · $B$ (where, according to Yalin 1992, const $\approx 2 \pi$ ), one obtains

$$
\frac{1}{c^{2}}=\varphi\left(\theta_{0}, B / h_{a v}, h_{a v} / k_{s}, v_{*} k_{s} / v\right)
$$


Eq. (13) implies that $1 / c_{M}^{2}$ in Eq. (7) must be expected to be at most a function of the four dimensionless variables on the right-hand side of Eq. (13), i.e. that

$$
\frac{1}{c_{M}^{2}}=\varphi\left(\theta_{0}, B / h_{a v}, h_{a v} / k_{s}, v_{*} k_{s} / v\right)
$$

[The fact that $1 / \mathrm{c}_{f}^{2}$ is determined by $h_{a v} / k_{s}$ and $v_{*} k_{s} / v$ does not exclude the possibility that $1 / \mathrm{c}_{M}^{2}$ too, may depend on these two variables].

For the case of fully rough flows, for which the conditions become independent of $v_{*} k_{s} / v$, Eq. (14) reduces to

$$
\frac{1}{c_{M}^{2}}=\varphi\left(\theta_{0}, B / h_{a v}, h_{a v} / k_{s}\right)
$$

It is noted that since $k_{s} \approx 2 D_{50}, h_{a v} / k_{s}$ in Eq. (15) is equivalent to $h_{a v} / D_{50}$, i.e. Eq. (15) is equivalent to

$$
\frac{1}{c_{M}^{2}}=\varphi\left(\theta_{0}, B / h_{a v}, h_{a v} / D_{50}\right)
$$

\section{Experimental Data}

\section{Description of Data}

The dataset used in this work consists of a total of 40 laboratory experiments and 285 field observations, reported by various authors. The data are summarized in table 1 , where $N$ is number of experiments or observations by a given author, $Q$ is flow rate, $D_{50}$ is representative grain size, $B$ is flow width, $h_{a v}$ is channel-averaged flow depth, $S_{c}$ is bed slope along the centreline of a meandering flow, and $\theta_{0}$ is deflection angle of a meandering flow at the crossover $O_{i}$.

Some authors provided the value of stream sinuosity $\sigma$ instead of $\theta_{0}$. For the present purpose, $\sigma$ was converted to $\theta_{0}$ with the aid of Eq. (3); the Bessel function $J_{0}\left(\theta_{0}\right)$ was calculated from the following polynomial approximation (see [6]):

$$
\begin{aligned}
J_{0}\left(\theta_{0}\right) \approx 1- & 2.2499997\left(\frac{\theta_{0}}{3}\right)^{2}+1.2656208\left(\frac{\theta_{0}}{3}\right)^{4}-0.3163866\left(\frac{\theta_{0}}{3}\right)^{6} \\
& +0.0444479\left(\frac{\theta_{0}}{3}\right)^{8}-0.0039444\left(\frac{\theta_{0}}{3}\right)^{10}+0.0002100\left(\frac{\theta_{0}}{3}\right)^{12}
\end{aligned}
$$

where $\theta_{0}$ is in radians. 
Table 1. Summary of the dataset used in this work (total of 40 laboratory experiments and 285 field observations).

\begin{tabular}{|c|c|c|c|c|c|c|c|c|c|c|}
\hline & Data Source & $N$ & $\theta_{0}\left({ }^{\circ}\right)$ & $Q\left(m^{3} / s\right)$ & $D_{50}(\mathrm{~mm})$ & $B(\mathrm{~m})$ & $h_{a v}(m)$ & $S_{c}(\%)$ & $\operatorname{Re}\left(x 10^{-3}\right)$ & $F r$ \\
\hline \multirow{10}{*}{ 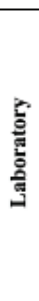 } & Binns and da Silva, 2009 & 5 & 70 & $0.007-0.014$ & 0.65 & 0.800 & $0.041-0.046$ & $2.5-8.0$ & $7.9-15.5$ & $0.284-0.577$ \\
\hline & Binns and da Silva, Bh Runs*, 2012 & 6 & 70 & $0.003-0.033$ & 0.65 & 0.800 & $0.014-0.156$ & $1.8-8.0$ & $4.0-29.5$ & $0.212-0.873$ \\
\hline & \begin{tabular}{|l|} 
da Silva and El-Tahawy, 2008 \\
\end{tabular} & 6 & 70 & $0.007-0.013$ & 0.65 & 0.800 & $0.035-0.075$ & $2.2-4.0$ & $7.5-14.2$ & $0.214-0.396$ \\
\hline & da Silva, El-Tahawy and Tape, 2006 & 3 & $30-110$ & 0.002 & 2.2 & 0.400 & $0.030-0.032$ & $0.001-1.0$ & $4.0-4.5$ & $0.269-0.309$ \\
\hline & Hasegawa, 1983 & 4 & $20-30$ & $0.001-0.002$ & 0.43 & $0.22-0.30$ & $0.009-0.026$ & $3.3-14.1$ & $2.3-5.3$ & $0.475-0.935$ \\
\hline & Holzwarth, 2006 & 2 & 70 & $0.002-0.006$ & 0.65 & 0.8 & $0.012-0.024$ & 8.0 & $2.5-7.2$ & $0.638-0.655$ \\
\hline & Hooke, 1974 & 4 & 55 & $0.01-0.05$ & 0.3 & 1.0 & $0.052-0.128$ & $2.1-2.2$ & $9.1-39.8$ & $0.269-0.382$ \\
\hline & Termini, 1996 & 1 & 110 & 0.007 & 0.65 & 0.50 & 0.030 & 3.7 & 11.6 & 0.799 \\
\hline & Whiting and Dietrich, 1993a & 6 & $10-20$ & $0.001-0.002$ & 0.67 & 0.25 & $0.014-0.020$ & $4.2-6.4$ & $3.5-5.7$ & $0.603-0.764$ \\
\hline & Whiting and Dietrich, 1993b & 3 & 100 & 0.001 & 0.62 & 0.25 & $0.015-0.017$ & $4.0-6.0$ & $3.4-4.2$ & $0.653-0.759$ \\
\hline \multirow{7}{*}{ 플 } & Annable, 1994 & 40 & $27-98$ & $2.27-98.73$ & $0.25-46.0$ & $4.36-48.70$ & $0.52-2.38$ & $0.33-38.0$ & $305.2-3493.7$ & $0.095-0.800$ \\
\hline & Chitale, 1970 & 23 & $38-93$ & $141.58-42475.27$ & $0.04-5.0$ & $54.86-2143.96$ & $1.52-20.12$ & $0.047-1.25$ & $2275.2-55741.8$ & $0.092-0.426$ \\
\hline & Davidson and Hey, 2011 & 32 & $35-97$ & $2.43-424.00$ & $17.0-130.0$ & $6.55-97.00$ & $0.298-3.90$ & $1.0-14.0$ & $340.1-6356.8$ & $0.267-0.728$ \\
\hline & Jan H van den Berg, 1994 & 57 & $57-97$ & $1.87-28000.00$ & $0.19-90.50$ & $5.21-1975.00$ & $0.30-10.60$ & $0.045-11.0$ & $279,4-16936,7$ & $0.015-0.697$ \\
\hline & \begin{tabular}{|l|} 
Schumm, 1968 \\
\end{tabular} & 13 & $35-94$ & $254.85-707.92$ & $0.4-1.3$ & $50.29-182.88$ & $2.44-9.45$ & \begin{tabular}{|l|}
$0.076-0.38$ \\
\end{tabular} & $3420.8-7102.7$ & $0.077-0.296$ \\
\hline & Thorne, 1993 & 16 & $16-114$ & $0.88-1796.40$ & $0.3-9.7$ & $4.0-231.5$ & $0.40-5.55$ & $0.117-2.14$ & $183.3-7678.2$ & $0.101-0.278$ \\
\hline & Thorne, 2001 & 104 & $35-103$ & $1.60-1451.50$ & $0.12-1.63$ & $9.5-225.0$ & $0.45-8.22$ & $0.07-0.88$ & $153.8-11010.0$ & $0.122-0.309$ \\
\hline
\end{tabular}

\section{Preliminary analysis of data}

In view of Eq. (16), a preliminary analysis of the data was carried out to assess whether $1 / c_{M}^{2}$ is a function of all of the dimensionless variables in the equation, namely $\theta_{0}, B / h_{a v}$ and $h_{a v} / D_{50}$.

In this analysis, only the data from controlled laboratory experiments is considered, as a means to eliminate data scatter that may obfuscate data trends. In all subsequent plots in this section, $1 / \mathrm{c}_{M}^{2}$ was obtained from the relation (see Eq. (7))

$$
\frac{1}{c_{M}^{2}}=\frac{1}{c^{2}}-\frac{1}{c_{f}^{2}}-\frac{1}{c_{\Delta}^{2}}
$$

in which $1 / \mathrm{c}^{2}$ was identified with the measured value of $\left(v_{*} / v\right)^{2}$, and $1 / \mathrm{c}_{f}^{2}$ and $1 / \mathrm{c}_{\Delta}^{2}$ were calculated from Eqs. (8) and (10), respectively. In the absence of observations on bed forms, the methods by [6] (see [15]) were used to establish whether dunes and/or ripples were present, and determine their geometric characteristics $\left(\delta_{d}, \Lambda_{d}, \delta_{r}, \Lambda_{r}\right)$ appearing in Eq. (10).

Consider first figure 4 , showing the plot of (measured) $\left(1 / \mathrm{c}_{M}^{2}\right) /\left(1 / \mathrm{c}^{2}\right)$ versus $\theta_{0}$. This figure provides a measure of the contribution of the meandering of the stream to the overall resistance to flow. Note that, for the data under consideration, $\left(1 / \mathrm{C}_{M}^{2}\right) /\left(1 / \mathrm{c}^{2}\right)$ varies from $\approx 0.02$ to $\approx 0.86$, indicating that the contribution of the meandering to the overall flow resistance varies from very small to substantial, depending on the conditions in the stream.

Figure 4 indicates also that the greater contributions due to meandering occur for intermediate values of $\theta_{0}\left(55^{\circ}<\theta_{0}<85^{\circ}\right)$, and that this contribution rapidly decreases for both small and large values of $\theta_{0}$, as the deviation of $\theta_{0}$ from $\approx 70^{\circ}$ increases. The same can also be inferred from figure 5 , showing plots of measured values of $1 / \mathrm{c}_{M}^{2}$ versus $\theta_{0}$. For the purposes of the present discussion, consider only the data in these plots: the solid lines will be introduced later, and for now they should be taken only as providing a means to highlight the data trend. Each plot in figure 5 includes the data within a given range of $B / h_{a v}$ values.

In addition, to show the above described trend of $1 / c_{M}^{2}$ with $\theta_{0}$, figure 5 shows that $1 / c_{M}^{2}$ is affected also by $B / h_{a v}$. Indeed, note how in the plots in figure 5 the maximum value of $1 / \mathrm{c}_{M}^{2}$ becomes smaller as $B / h_{a v}$ increases. For example, in the plot at the top left in figure 5 , corresponding to $5<B / h_{a v} \leq 15$, the average of $1 / \mathrm{c}_{M}^{2}$ values of the data for $\theta_{0}=70^{\circ}$ is 0.022 ; while in the plot at the bottom right, corresponding to $40<B / h_{a v} \leq 70$, it is 0.008 . 
The dependency of $1 / C_{M}^{2}$ on $B / h_{a v}$ is also evident from figure 6 , in which the measured values of $1 /$ $C_{M}^{2}$ are plotted versus $B / h_{a v}$ and the data are sorted by values of $\theta_{0}$. Note that the solid and dashed lines in this figure were added merely to highlight the data patterns. Figure 6 clearly indicates that for any given value of $\theta_{0}, 1 / c_{M}^{2}$ decreases with the increment of $B / h_{a v}$, eventually becoming independent of $B / h_{a v}$ when $B / h_{a v}$ becomes sufficiently large.

As is well-known, the intensity of cross-circulatory motion in a bend depends directly on $B / R$ (the stream curvature) and decreases with increasing values of $B / h_{a v}$. The form of variation of $1 / c_{M}^{2}$ with $\theta_{0}$ described above and its decrease with $B / h_{a v}$ are consistent with the known form of variation of the intensity of cross-circulatory motion with these variables (recall in figure 2 , showing the graph of $B$ / $R_{a}$ versus $\theta_{0}$ for sine-generated streams).

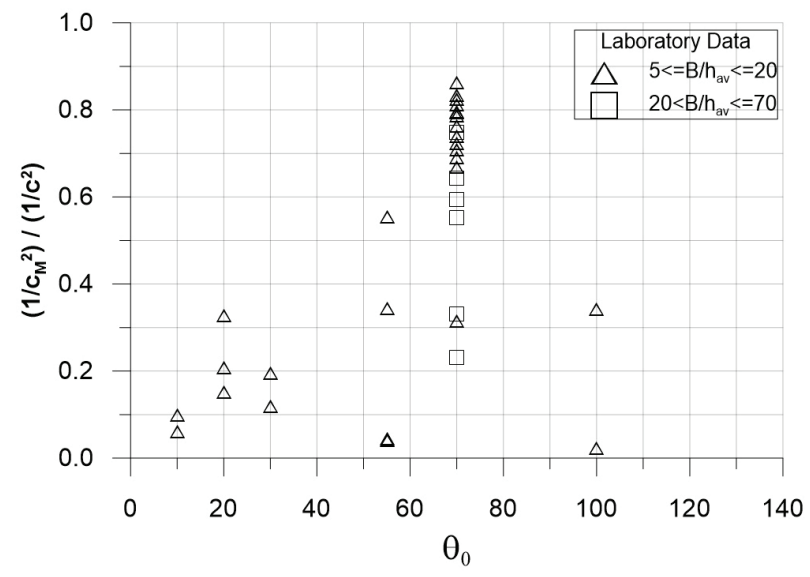

Figure 4. Plot of (measured) $\left(1 / \mathrm{c}_{M}^{2}\right) /\left(1 / \mathrm{c}^{2}\right)$ versus $\theta_{0}$
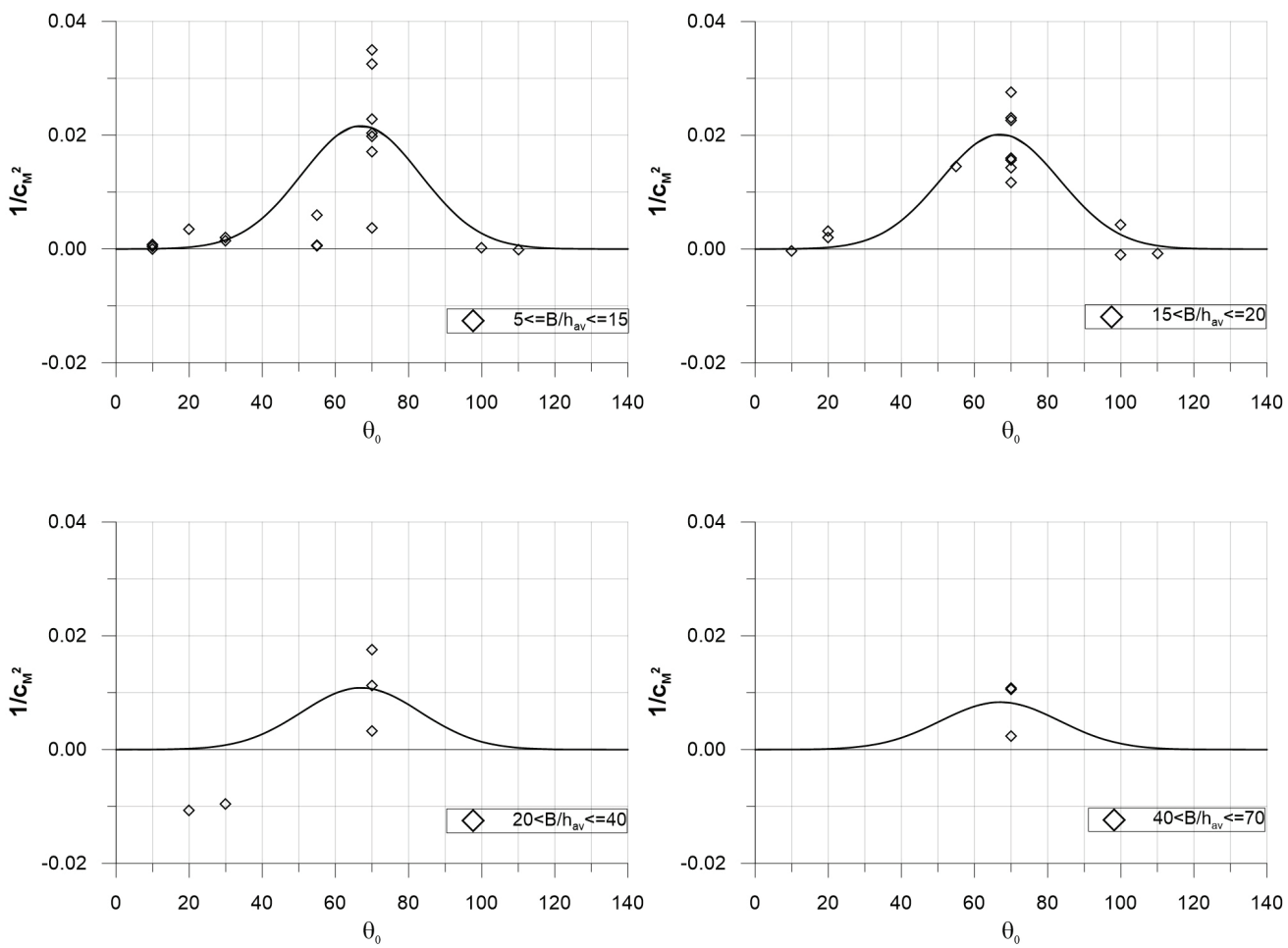

Figure 5. Variation of $1 / \mathrm{c}_{M}^{2}$ versus $\theta_{0}$, with the data sorted by $B / h_{a v}$. 
Finally, consider figure 7 , showing the plot of measured $1 / \mathrm{c}_{M}^{2}$ values versus $h_{a v} / D_{50}$. Like in figure 6 , the dashed line was added merely to highlight the data pattern. From figure 7 , it is clear that $1 / \mathrm{C}_{M}^{2}$ is also affected by $h_{a v} / D_{50}$, as the data exhibit a clear trend. Since the intensity of cross-circulatory motion is also affected by $h_{a v} / D_{50}$, it should not be surprising that $1 / \mathrm{c}_{M}^{2}$ is affected by it.

From the aforementioned, it follows that all three of $\theta_{0}, B / h_{a v}$ and $h_{a v} / D_{50}$ affect $1 / c_{M}^{2}$. Accordingly, the new equation was developed on the basis of Eq. (16) as it stands.

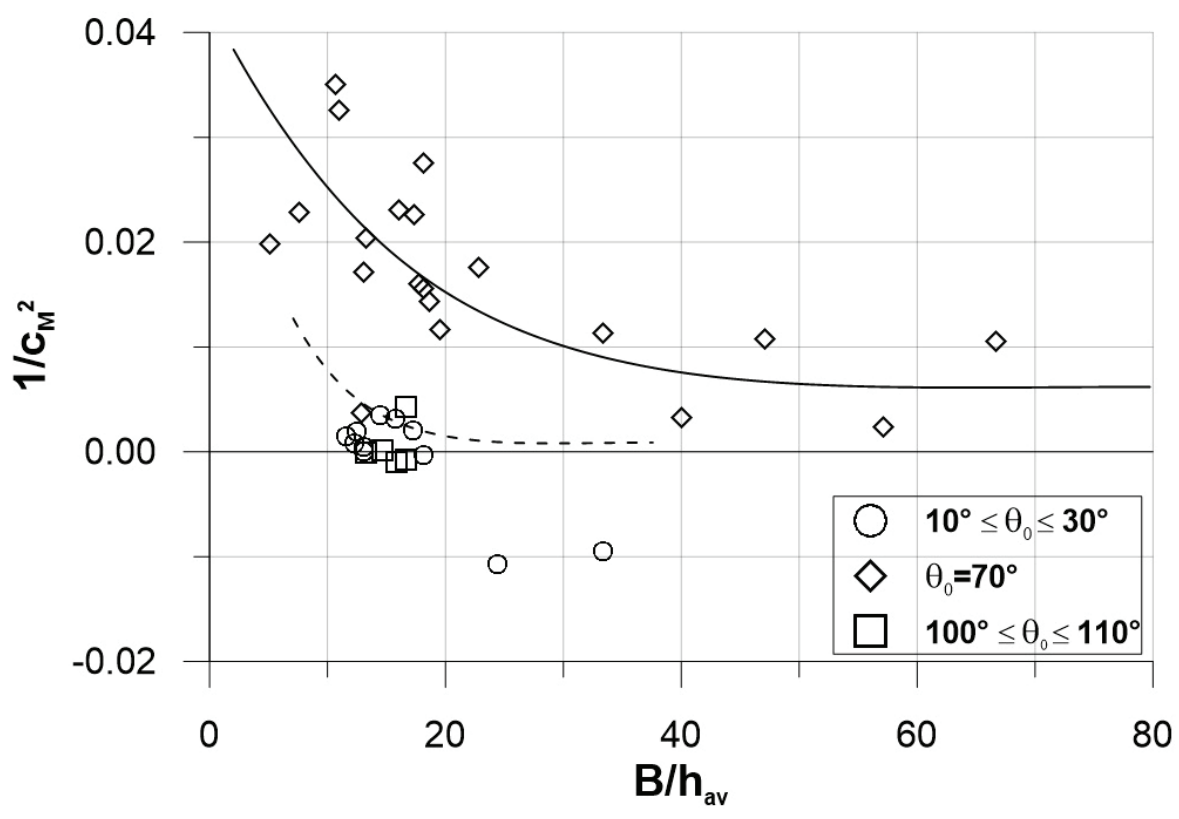

Figure 6. Dependecy of $1 / \mathrm{c}_{M}^{2}$ on $B / h_{a v}$

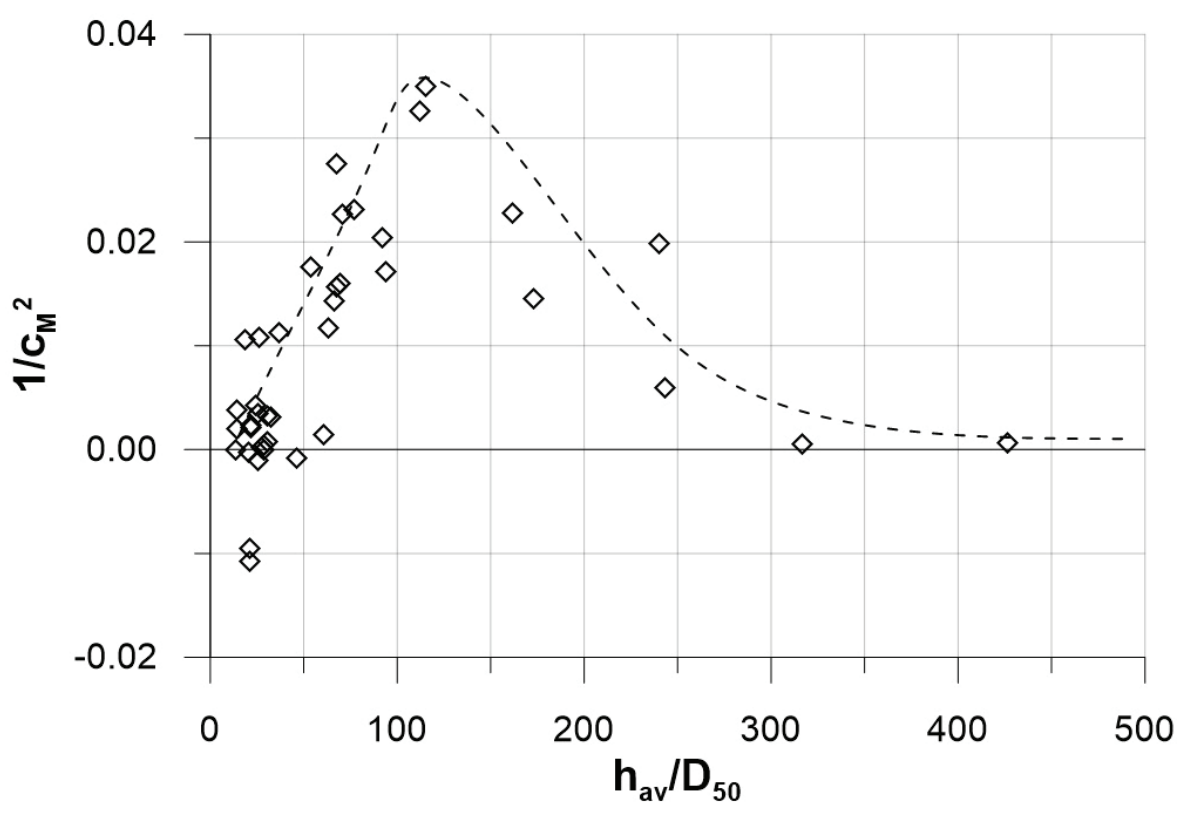

Figure 7. Plot of measured $1 / \mathrm{C}_{M}^{2}$ values versus $h_{a v} / D_{50}$. 


\section{Equation for $1 / \mathrm{c}_{M}^{2}$}

By analyzing the data patterns in view of Eq. (16) (see [15]), it was concluded that $1 / \mathrm{c}_{M}^{2}$ can be adequately represented by the following equation:

$$
\frac{1}{c_{M}^{2}}=a_{1} \cdot \varphi\left(\frac{h_{a v}}{D_{50}}\right) \cdot\left(\frac{B}{h_{a v}}\right)^{-0.625} e^{-\left(2.5 \theta_{0}-2.924\right)^{2}},
$$

where:

$$
\begin{array}{ll}
a_{1}=0.1 & \text { if } 5 \leq B / h_{a v} \leq 20, \\
a_{1}=0.062 & \text { if } B / h_{a v}>20,
\end{array}
$$

and:

$$
\begin{array}{ll}
\varphi\left(\frac{h_{a v}}{D_{50}}\right)=-1.03 \cdot \log \left(\frac{h_{a v}}{D_{50}}\right)+3.03 & \text { if } \frac{h_{a v}}{D_{50}} \leq 500, \\
\varphi\left(\frac{h_{a v}}{D_{50}}\right)=0.25 & \text { if } \frac{h_{a v}}{D_{50}}>500 .
\end{array}
$$

The graphs of Eq. (18) for $B / h_{a v}=10$ and 5000 (and $B / h_{a v}=10,17.5,30$ and 55) are shown in figure 8.

It should be noted that the solid lines on the plots in figure 5 are the graphs of Eq. (19). In each of these plots, the solid line was determined from Eq. (19) using as $B / h_{a v}$ value the average of the $B / h_{a v}$ and $B / h_{a v}$ values of the data in each plot.
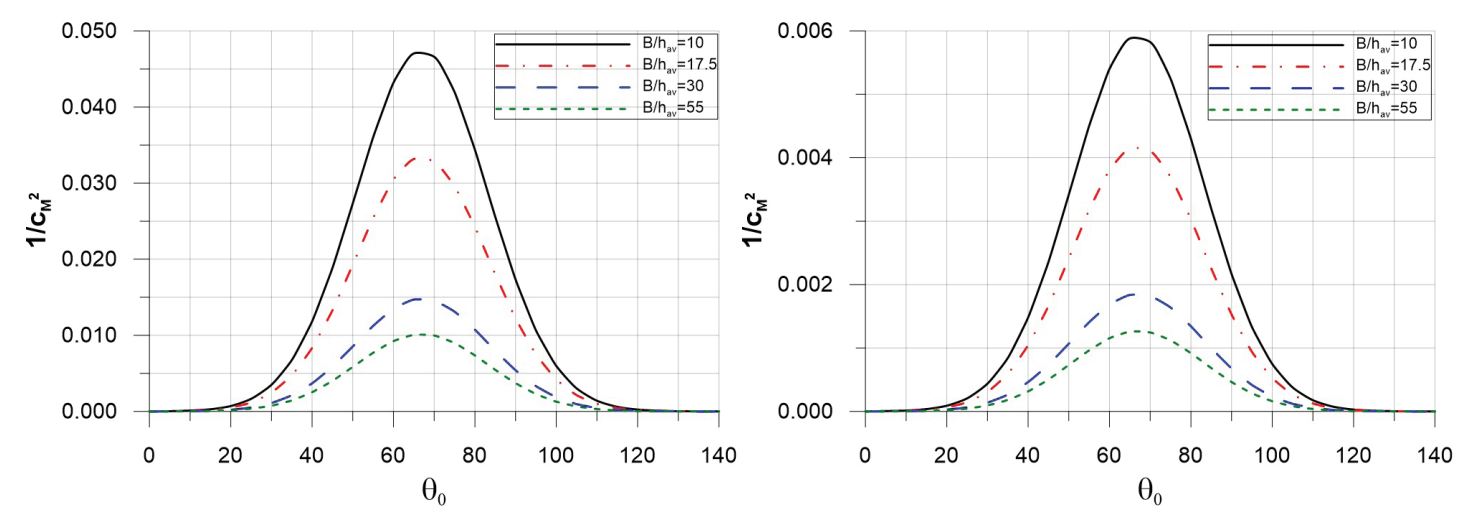

Figure 8. Graphs of present $1 / \mathrm{C}_{M}^{2}$-equation (Eq. (28)) for $h_{a \nu} / D_{50}=10$ (left) and $h_{a v} / D_{50}=5000$ (right), and selected values of $B / h_{a v}$.

\section{Results}

\section{Results of new method}

The results of application of the new method to the dataset previously described are shown in figures

Figure 9 (top left) shows the plot of $\left(u_{a v}\right)_{\text {Calculated }}$ versus $\left(u_{a v}\right)_{\text {Measured }}$ in which $u_{a v}$ is average flow velocity; 
Figure 9 (top right) depicts the residual plot, in which the abscissa is $\left(u_{a v}\right)_{\text {Measured }}$ and the ordinate is $\left[\left(u_{a v}\right)_{\text {Measured }}-\left(u_{a v}\right)_{\text {Calculated }}\right] /\left(u_{a v}\right)_{\text {Calculated }}$; and figure 9 (bottom) shows the probability density function of the residuals in the figure of the top right. For the laboratory data, the equation yields 80 and $98 \%$ of the data falling in the 20 and $40 \%$ error ranges, respectively; and for the field data, it yields 54 and $78 \%$ of the data falling in the same error ranges (see table 2). By considering the totality of the data, it yields 57 and $80 \%$ of the data falling in the 20 and $40 \%$ error ranges, respectively (table 2). The data are reasonably well distributed around the perfect agreement line (in figure 9 top left); the residuals do not exhibit a trend (figure 9 top right) and they closely follow a normal distribution (figure 9 bottom). These characteristics of the residual plot and the residuals probability density function indicate that the present equation is properly formulated.

Figure 10 shows the plots of calculated versus measured flow rate $Q$. Two plots are presented, one corresponding to $0.0001 \mathrm{~m}^{3} / \mathrm{s} \leq \mathrm{Q} \leq 0.1 \mathrm{~m}^{3} / \mathrm{s}$ and $0.1 \mathrm{~m}^{3} / \mathrm{s} \leq Q \leq 100000 \mathrm{~m}^{3} / \mathrm{s}$, so as to make the data in each plot clearly visible. It should be noted that since $Q=u_{a v} h_{a v} B$, the percentages of data falling within the 20 and $40 \%$ ranges are the same as for $u_{a v}$ (i.e. as shown in table 2).
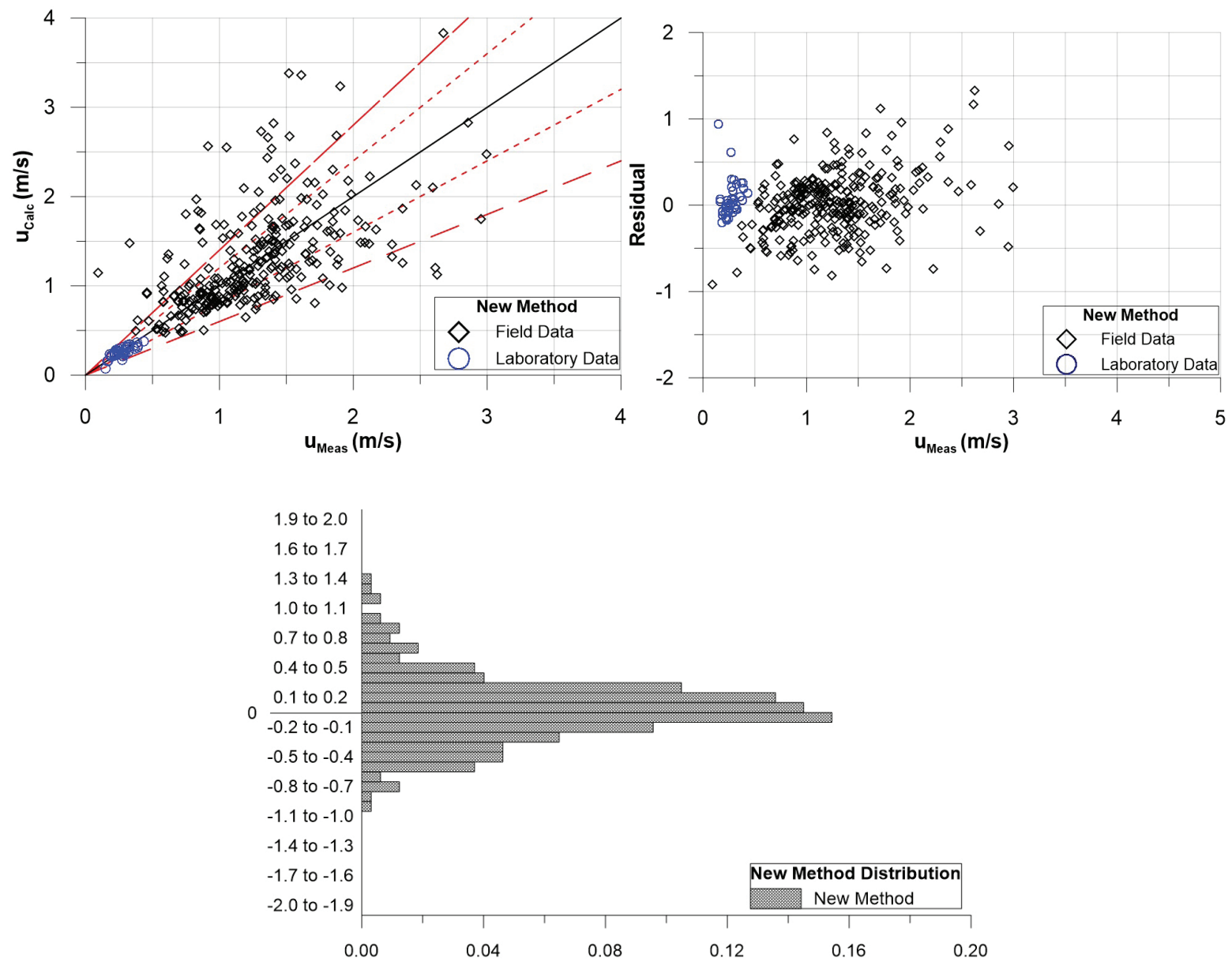

Figure 9. Comparison of calculated versus measured values of average flow velocity. Top left: plot of calculated versus measured $u_{a v}$; top right: residual plot; bottom: probability density function of the residuals. 
Table 2. Percentages of calculated $u_{a v}$ values within different error ranges for the present method.

\begin{tabular}{|c|c|c|c|}
\hline Error Range & (\%) Field & (\%) Laboratory & $(\%)$ Total \\
\hline $0-20 \%$ & 54 & 80 & 57 \\
\hline $0-40 \%$ & 78 & 98 & 80 \\
\hline $0-60 \%$ & 87 & 100 & 89 \\
\hline
\end{tabular}
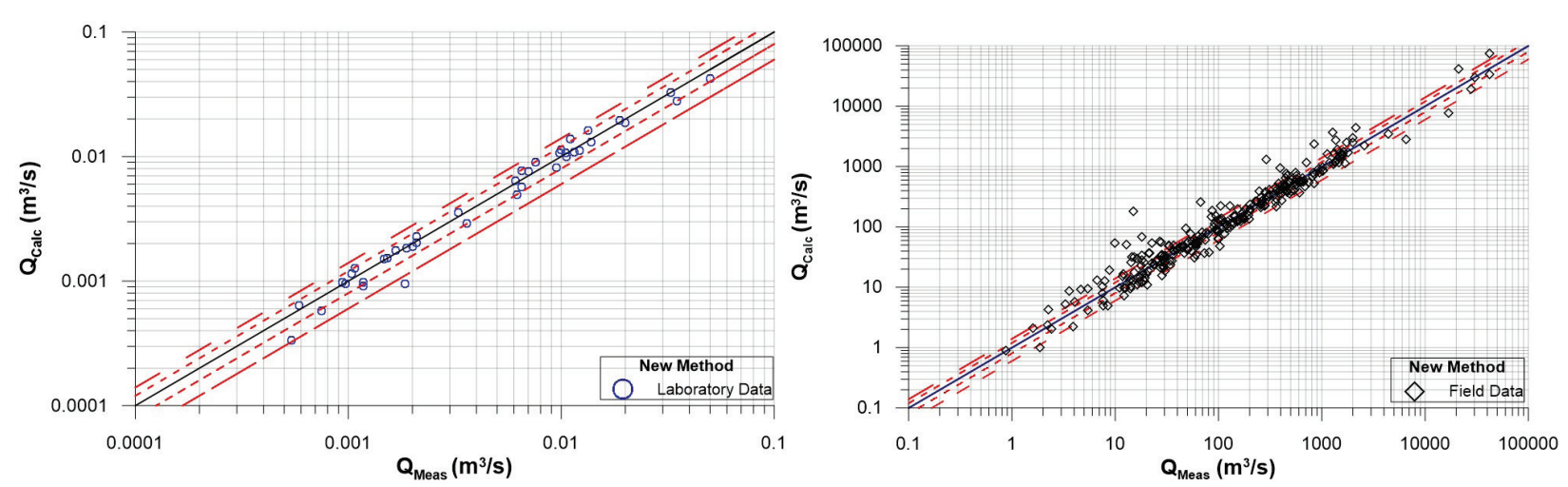

Figure 10. Plot of calculated versus measured flow rate for the present method.

\section{Comparison with previous methods}

We start by comparing the new method, in which $1 / \mathrm{c}^{2}$ is given by Eq. (7) with $1 / \mathrm{c}_{M}^{2}$ as defined by Eq. (19), with the previous method by da Silva and Yalin (2017) and based on Eq. (5). For this purpose, plots of $\left(u_{a v}\right)_{\text {Calculated }}$ versus $\left(u_{a v}\right)_{\text {Measured }}$ and $Q_{\text {Calculated }}$ versus $Q_{\text {Measured, }}$ similar to those in figure 9 and 10 , were produced as shown in figure 11 and 12, respectively. The related residual plot and the probability density function of the residuals can be consulted in Appendix C from Gamboa (2018).

As can be inferred from figures 11 and 12, the non-inclusion of a term to consider the meandering of the stream when calculating the resistance factor c leads to systematic over-estimation of the flow velocity and, consequently, flow rate. Note from figure 11 that the data plot around the upper $20 \%$ error range line, instead of being aligned with the perfect agreement line. This means that by not including the term $1 / \mathrm{c}_{M}^{2}$, velocity and flow rate are overestimated on average by $20 \%$.
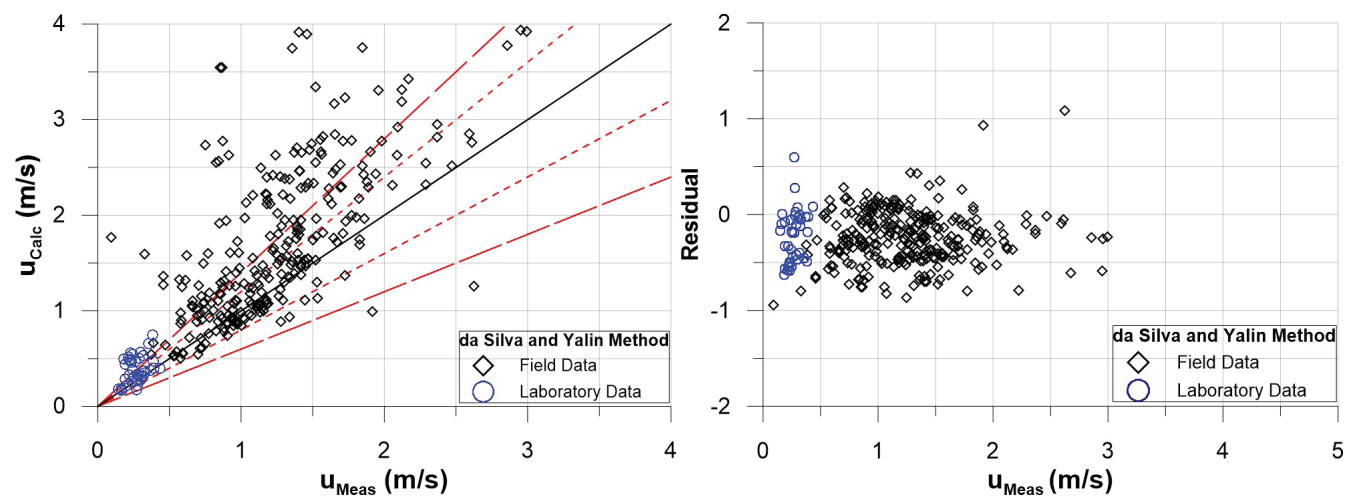

Figure 11. Comparison of calculated versus measured values of average flow velocity. Left: plot of calculated versus measured $u_{a v}$; right: residual plot. 

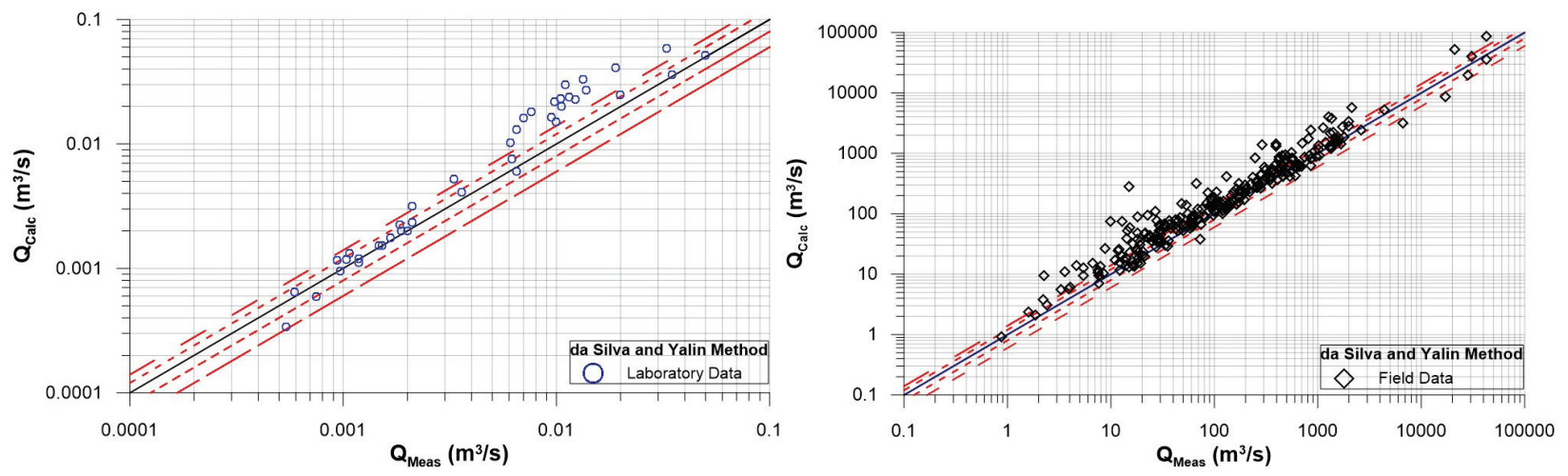

Figure 12. Plots of calculated versus measured flow rate for da Silva and Yalin method.

We proceed now to evaluate the present method against previous methods [3] and [5].

The SCS and LSCS methods require selection of the value of Manning's n; and the method by James and Wark [5] requires adoption of the value of Darcy-Weisbach friction factor $f$. In the absence of detailed information on the streams, for the present purposes, the value $n=0.03$ was adopted for all cases (laboratory and field data). This is justified on the basis of Arcement and Schneider [16] and Villon [17].

The following expression, due to [18] (see also e.g. [19]) was adopted for $f$ :

$$
\frac{1}{\sqrt{f}}=2.0 \log \left(\frac{h_{a v}}{D_{50}}\right)+1.0
$$

where $D_{84}$ is $84^{\text {th }}$ percentile used to represent the coarse fraction. The values of $D_{84}$ of the bed material of the streams in the database are, in general, not known. For this reason, $f$ was determined from Eq. (24) using $D_{50}$ instead of $D_{84}$. A sensitivity analysis was carried out to evaluate differences in the results by adopting instead of $D_{84}$ both $D_{50}$ and $k_{s}=2 D_{50}$. It was found that the results obtained with $2 D_{50}$ are substantially worse than those obtained with $D_{50}$ (hence the reason to adopt $D_{50}$ in the calculation).

Similarly to figure 11, figures 13,14 and 15 show the plots of $\left(u_{a v}\right)_{\text {Calculated }}$ versus $\left(u_{a v}\right)_{\text {Measured }}$ (figures on the left) and the residual plots (figures on the right). The probability density functions of the residuals and the plots of calculated versus measured flow rate $Q$ can be consulted in Appendix C. The percentage of calculated $u_{a v}$-values falling within the 20, 40 and $60 \%$ error ranges for the three methods under consideration are shown in table 3.

As follows from figures 9 and 13-15:

- The present method yields substantially improved results for the laboratory data.

- The present method eliminates the trends of previous methods to underestimate both velocity and flow rates. 

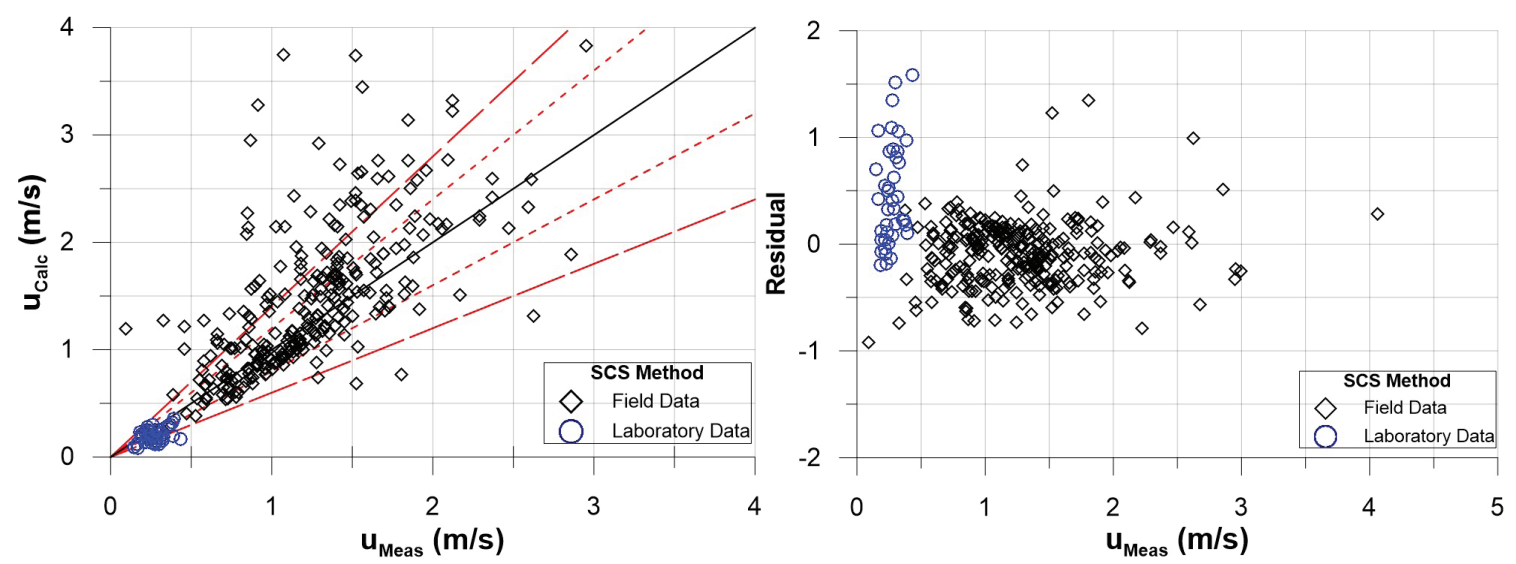

Figure 13. Comparison of calculated versus measured values of average flow velocity. Left: plot of calculated versus measured $u_{a v}$; right: residual plot.
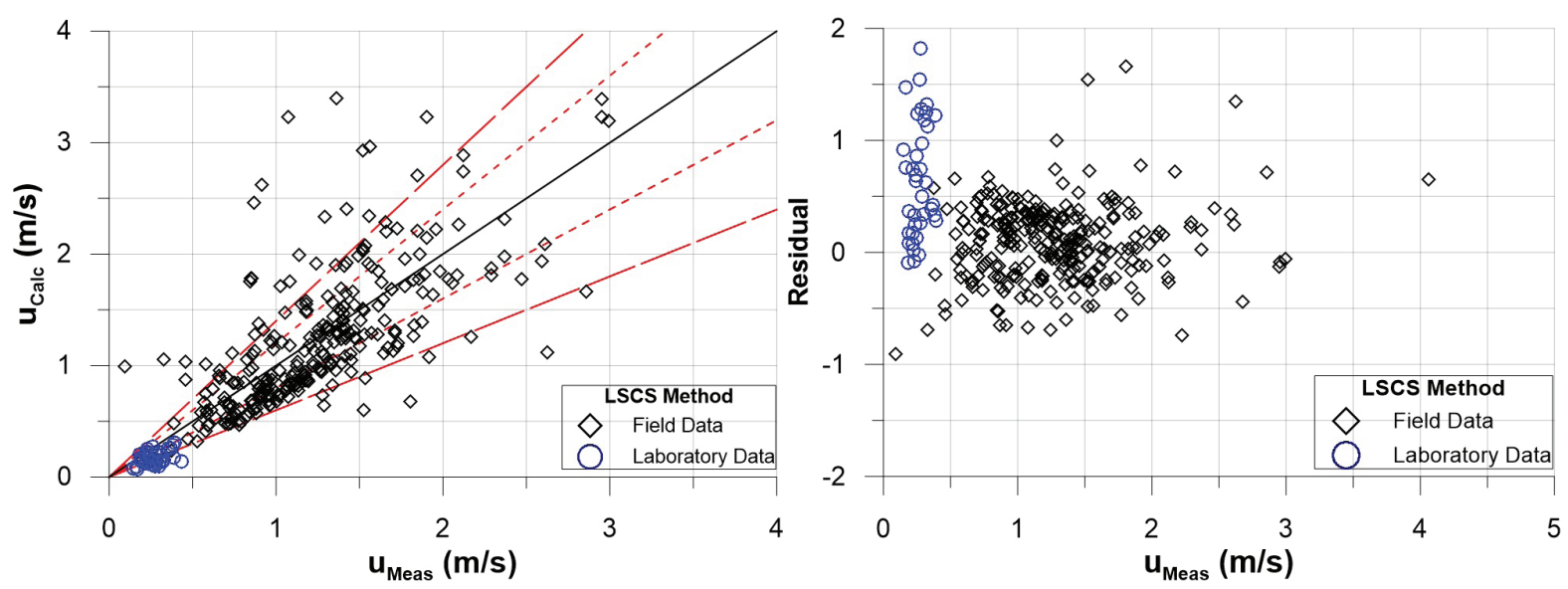

Figure 14. Comparison of calculated versus measured values of average flow velocity. Left: plot of calculated versus measured $u_{a v}$; right: residual plot.
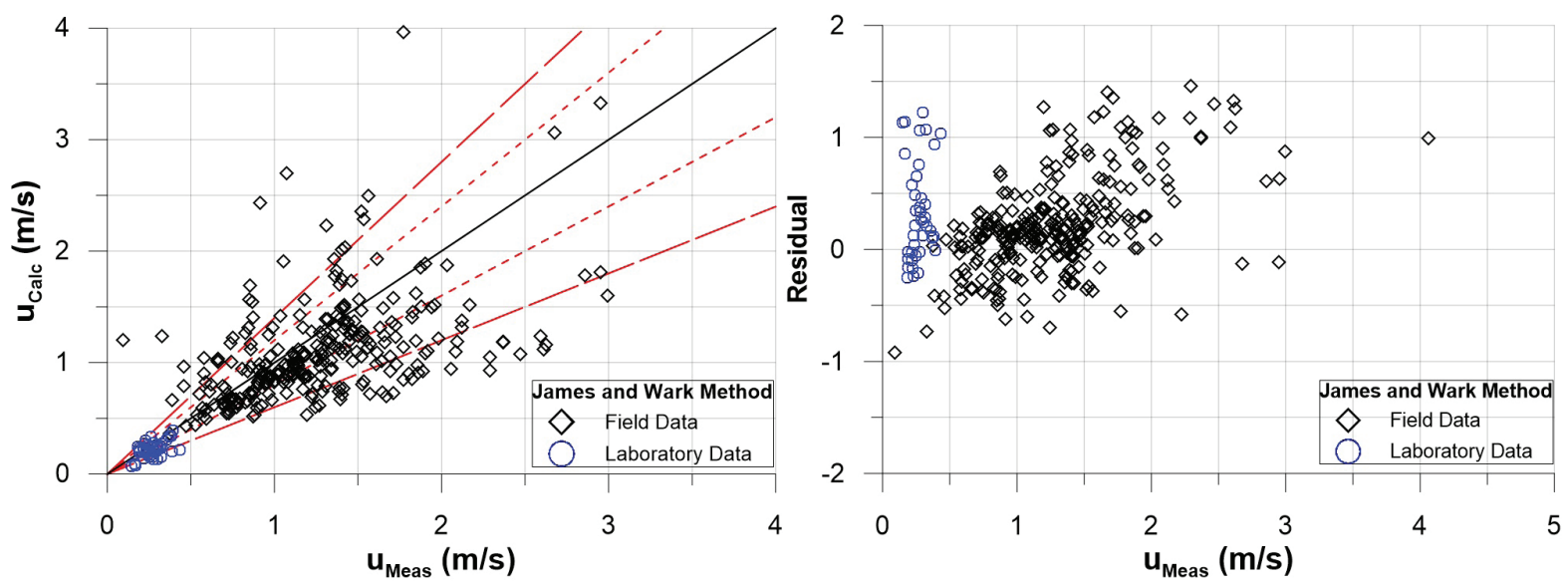

Figure 15. Comparison of calculated versus measured values of average flow velocity. Left: plot of calculated versus measured $u_{a v}$; right: residual plot. 
Table 3. Percentages of calculated $u_{a v}$ values within different error ranges for the SCS method, LSCS method and James and Wark method.

\begin{tabular}{|c|c|c|c|}
\hline \multicolumn{4}{|c|}{ Soil Conservation Service Method (SCS) 1963} \\
\hline Error Range & $(\%)$ Field & $(\%)$ Laboratory & (\%) Total \\
\hline $0-20 \%$ & 42 & 23 & 40 \\
\hline $0-40 \%$ & 84 & 50 & 80 \\
\hline $0-60 \%$ & 91 & 90 & 91 \\
\hline \multicolumn{4}{|c|}{ Linearized Soil Conservation Service Method (LSCS) 1963} \\
\hline Error Range & (\%) Field & (\%) Laboratory & (\%) Total \\
\hline $0-20 \%$ & 43 & 23 & 40 \\
\hline $0-40 \%$ & 85 & 53 & 81 \\
\hline $0-60 \%$ & 91 & 90 & 91 \\
\hline Error Range & James and Wark Method 1992 & (\%) Total \\
\hline $0-20 \%$ & $(\%)$ Field & $(\%)$ Laboratory & 47 \\
\hline $0-40 \%$ & 48 & 43 & 75 \\
\hline $0-60 \%$ & 75 & 78 & 94 \\
\hline
\end{tabular}

\section{Conclusions}

According to the analysis and discussion made previously, it is possible to conclude the following:

- The contribution of the meandering of the stream to the overall resistance to flow varies from negligible to very substantial, depending on the stream geometric and flow conditions: negligible in small and large sinuosity streams having large values of the width-to-depth ratio, and very substantial in streams having intermediate values of sinuosity and values of width-to-depth ratio less than $\approx 20$.

- The additional resistance to flow due to meandering of the stream is directly linked to the intensity of cross-circulation, and thus exhibits a similar form of the variation with $\theta_{0}$ and a similar decrease with $B / h_{a v}$. The convective behaviour of flow because of curvature variation along $I_{c}$ has a comparatively small effect on the overall resistance to flow.

- The present work proves that the resistance to flow term due to the meandering of the stream depends on the width-to-depth ratio $\left(B / h_{a v}\right)$, depth-to-grain size ratio $\left(h_{a v} / D_{50}\right)$ and the values of deflection angle of a meandering flow at the crossover $O_{i}$.

- According to the graphs and the error ranges that were shown previously, it is possible to conclude that the present equation approach has a higher accuracy than the other methods that were jointly analyzed.

- Finally, it is important to mention that for using the present equation it is not necessary to make assumptions in any case, which does not occur in the other methods that were jointly tested; while the other methods require selection of Manning's $n$ values from different tables that use a random and personal criterion, which varies depending on the evaluator. Besides, the James and Wark method requires the Darcy Weisbach coefficient, which depends on Reynolds number, making the calculations difficult in some cases. 


\section{Acknowledgements}

I would like to express my deep gratitude to my mother Yamilette Monge Carranza, my father Alexander Gamboa Pacheco and my sister Dahayana Gamboa Monge for the enthusiastic encouragement and in general the support that they offered to me during the all process, because this would not have been possible without them.

I would also like to thank Eng. Marvin Villalobos and Eng. Fernando Watson, for the advice and assistance in keeping my progress on schedule. My grateful thanks are also extended to the staff of the School of Agricultural Engineering and the Vice-rectory of Student Life and Academic Services of Tecnológico de Costa Rica for their support through the academic procedures and partial funding. Besides, I wish to thank to the staff of Queen's University for giving me the opportunity to study in such a prestigious institution.

Finally, I would like to offer my most sincere thanks to Valeria Marin and her family, and also to Chris Trimmer, Cornel Florea, Shane Singh, Brennen Heenan, Daniel Perry and all my other friends for helping me in different ways throughout this process and for making this experience something unforgettable.

\section{References}

[1] V. Chow, "Open channels and their properties," in Open-Channel Hydraulics. United States of America: McGraw-Hill Company, 1976, pp.19-32.

[2] C. S. James, Evaluation of methods for predicting bend loss in meandering channels, vol. 120, issue 2. American Society of Civil Engineers: Journal of Hydraulic Engineering, 1994.

[3] Soil Conservation Service, Guide for selecting roughness coefficient " $n$ " value for channels. Soil Conservation Service (SCS), U. S. Dept. of Agric., Washington, DC, 1963.

[4] L. B. Leopold, R. A. Bagnold, M. G. Wolman and L. M. Brush, Flow resistance in sinuous or irregular channels, paper 282-D. USGS Professional Paper, Geological Survey, Washington, DC, 1960, pp. 111-134.

[5] C. S. James and J. B. Wark, "Conveyance estimation for meandering channels," HR Wallingford, Rep. 329, 1992.

[6] A. M. F. da Silva and M. S. Yalin, Fluvial Processes, 2nd ed. IAHR Monograph Series, CRC Press/Balkema, Taylor \& Francis Group, Leiden, The Netherlands, 2017, 266 pages.

[7] W. B. Langbein and L. B. Leopold, Theory of Minimum Variance, paper 422-H. Physiographic and Hydraulic Studies of Rivers, Geological Survey Professional Paper, United States Government Printing Office, Washington, DC, 1966.

[8] H. A. Einstein and N. Barbarossa, River channel roughness, vol. 117. Trans., ASCE, 1952.

[9] F. Engelund, Hydraulic resistance of alluvial streams, vol. 92, issue 2. Journal of the Hydraulics Division, ASCE, 1966, pp. 315-326.

[10] M. S. Yalin, On the average velocity of flow over a mobile bed, No. 1. La Houille Blanche, 1964, pp. 45-51.

[11] M. S. Yalin, Mechanics of sediment transport, 2nd ed. Pergamon Press, Oxford, 1977.

[12] J. W. Kamphuis, Determination of sand roughness for fixed beds, vol. 13, issue 2. Journal of Hydraulic Research, 1974, pp. 193-203.

[13] M. S. Yalin, River mechanics. Pergamon Press, Oxford, 1992.

[14] A. M. F. da Silva and T. Bolisetti, A method for the formulation of Reynolds number functions, vol. 24, issue 4. Canadian Journal of Civil Engineering, 2000.

[15] C. A. Gamboa, "A new method to predict average flow velocity and conveyance capacity of meandering streams," Undergraduate Thesis, Agricultural Engineering School, Tecnológico de Costa Rica, Cartago, Costa Rica (In Spanish), 2018.

[16] G. J. Arcement and V. R. Schneider, Guide for Selecting Manning's Roughness Coefficients for Natural Channels and Flood Plains. United States of America: United States Government Printing Office, 1989.

[17] M. Villón, Hidráulica de Canales. Cartago, Costa Rica: Ediciones Centro de Desarrollo de Material Bibliográfico (CDMB), 2008.

[18] L. B. Leopold, M. G. Wolman and J. P. Miller, Fluvial Processes in Geomorphology. San Francisco: Freeman, 1964, $522 \mathrm{p}$.

[19] K. Whipple, Surface Processes and Landforms. Office of Digital Learning, Massachusetts Institute of Technology (MIT), United States of America, 2002. 